\title{
Evodiamine inhibits proliferation and induces apoptosis in gastric cancer cells
}

\author{
HUAMEI SHEN ${ }^{1}$, SHUAI ZHAO ${ }^{2}$, ZHIPENG XU ${ }^{2}$, LIHUA ZHU ${ }^{3}$, YUEHUA HAN ${ }^{2}$ and JUN YE ${ }^{2}$ \\ Departments of ${ }^{1}$ Infectious Disease and ${ }^{2}$ Gastroenterology, The Second Affiliated Hospital, \\ Zhejiang University School of Medicine, Hangzhou, Zhejiang 310009; ${ }^{3}$ Department of Hyperbaric Oxygen Chamber, \\ The Xinhua Hospital of Zhejiang, Hangzhou, Zhejiang 310009, P.R. China
}

Received June 22, 2014; Accepted March 26, 2015

DOI: $10.3892 / \mathrm{ol} .2015 .3153$

\begin{abstract}
In the present study, the effects of evodiamine on the apoptosis of human gastric cancer cells was studied in order to assess its antitumor effects and identify the molecular mechanisms involved. SGC7901 gastric cancer cells were treated with evodiamine at various concentrations $(0,3,6$, 12,24 and $48 \mu \mathrm{mol} / \mathrm{l}$ ) for $24 \mathrm{~h}$. Inhibition of the proliferation of SGC7901 cells was assessed using an MTT assay. The morphology of treated SGC7901 cells was observed using optical microscopy; in addition, the effect of evodiamine on the nuclear morphology of cells was analyzed using Hoechst 33258 staining with fluorescence microscopy. Annexin V-fluorescein isothiocyanate/propidium iodide staining and flow cytometric analysis were used for investigating the effect of evodiamine on the induction of apoptosis in SGC7901 cells. Expression levels of survivin and caspase-3 were examined using reverse transcription polymerase chain reaction. The results demonstrated that evodiamine significantly inhibited SGC7901 cell proliferation $(\mathrm{P}<0.05)$ and induced apoptosis in a dose-dependent manner $(\mathrm{P}<0.05)$. Morphological characteristics of apoptosis were confirmed using optical microscopy and Hoechst 33258 staining analysis indicated that evodiamine treatment resulted in the typical characteristics of apoptotic programmed cell death, including cell shrinkage and apoptotic body formation. Flow cytometric analysis demonstrated that evodiamine induced the dose-dependent apoptosis of SGC7901 cells. Messenger (m)RNA levels of survivin decreased and those of caspase- 3 increase in a dose-dependent manner in SGC7901 cells treated with various concentrations of evodiamine for $24 \mathrm{~h}$. In conclusion, the results of the present study demonstrated that evodiamine inhibited
\end{abstract}

Correspondence to: Dr Yuehua Han or Dr Jun Ye, Department of Gastroenterology, The Second Affiliated Hospital, Zhejiang University School of Medicine, 88 Jiefang Road, Hangzhou, Zhejiang 310009, P.R. China

E-mail: hanyh_2012@aliyun.com

E-mail:wzmcyejun@zju.edu.cn

Key words: evodiamine, gastric cancer, apoptosis, survivin, caspase-3 proliferation and induced apoptosis in gastric cancer cells via the downregulation of survivin and upregulation of caspase-3 mRNA.

\section{Introduction}

The balance between cell growth and death is critical for the maintenance of normal tissue architecture (1). However, the disorder of these processes has been implicated in numerous pathological conditions, including the pathogenesis of cancer $(2,3)$. Therefore, inhibition of cell proliferation and induction of apoptosis may result in the effective treatment of various types of cancer. Survivin is a member of the inhibitor of apoptosis family of proteins, which inhibits apoptosis and significantly promotes cell proliferation (4). Caspase-3 is a key mediator of apoptosis that regulates programmed cell death via two main pathways: The mitochondrial pathway (intrinsic pathway) and the death receptor pathway (extrinsic pathway) (5).

Evodia rutaecarpa has previously been used in Traditional Chinese medicine and was reported to have various biological functions, including the inhibition of influenza virus-induced inflammation (6) as well as type I and II topoisomerases (7); in addition, Evodia rutaecarpa is a source of natural larvicides (8). Evodiamine was identified as one of the major active substances of Evodia rutaecarpa $(5,9)$. Previous studies have reported the antitumor activity of evodiamine; one study demonstrated that evodiamine was able to inhibit proliferation of human thyroid cancer cells through cell cycle arrest at $\mathrm{M}$ phase and the induction of apoptosis (10). In addition, evodiamine was found to inhibit the growth of prostate cancer cells via the induction of apoptosis (11). However, the antitumor effect of evodiamine in gastric cancer cells remains to be elucidated.

In the present study, SGC7901 human gastric cancer cells were treated with various concentrations of evodiamine for $24 \mathrm{~h}$ in order to assess the effect of evodiamine on the regulation of cell proliferation and apoptosis as well as to identify the molecular mechanism involved in its antitumor effects.

\section{Materials and methods}

Cell lines. The SGC7901 human gastric cancer cell line was purchased from the Cell Bank of the Chinese Academy of Medical Science (Beijing, China) and cells were cultured in 
RPMI 1640 medium (Gibco-BRL, Carlsbad, CA, USA) supplemented with $10 \%$ fetal bovine serum (FBS; Gibco-BRL). Cells were maintained at $37^{\circ} \mathrm{C}$ in a humidified $5 \% \mathrm{CO}_{2}$ atmosphere and passaged every $2-4$ days.

MTT assay for cell proliferation. SGC7901 cells were seeded at a density of $5 \times 10^{3}$ cells per well in a 96-well plate containing $0.2 \mathrm{ml} \mathrm{RPMI} 1640$ medium with $10 \% \mathrm{FBS}$ and cultured for $24 \mathrm{~h}$ at $37^{\circ} \mathrm{C}$ in a humidified atmosphere of $5 \% \mathrm{CO}_{2}$. Cells were then treated with various concentration of evodiamine $(0,3,6,12,24$ and $48 \mu \mathrm{mol} / \mathrm{l})$ in $200 \mu \mathrm{l}$ RPMI 1640 medium and incubated for a further $24 \mathrm{~h}$. Following incubation, $20 \mu \mathrm{l}$ freshly prepared and filtered MTT (Sigma-Aldrich, St Louis, MO, USA) was added to each well at a final concentration of $5 \mathrm{mg} / \mathrm{ml}$ and incubated for $3 \mathrm{~h}$. The medium was then removed and cells in each well were dissolved in $100 \mu \mathrm{l}$ dimethyl sulfoxide (Sangon Biological Engineering Technology and Services Co., Ltd, Shanghai, China). Absorbance values were measured at $570 \mathrm{~nm}$ using a microplate reader (680; Bio-Rad Laboratories, Inc., Hercules, CA, USA). The following formula was used to calculate the inhibitory rate: Cells inhibition rate $=[1$ - average optical density $(\mathrm{OD})$ value of treatment group/average OD value of control group] x $100 \%$.

Morphological observation of apoptosis. SGC7901 cells were seeded at a density of $5 \times 10^{4}$ cells per well on coverslips in six-well plates. Once cells had reached the logarithmic growth phase, evodiamine was administered at concentrations of 0 , $3,6,12,24$ and $48 \mu \mathrm{mol} / 1$ and cells were cultured for $24 \mathrm{~h}$ at $37^{\circ} \mathrm{C}$ in a humidified atmosphere of $5 \% \mathrm{CO}_{2}$. Morphological changes were observed under an inverted phase contrast microscope (DMI4000; Leica, Wetzlar, Germany). Supernatant was collected and centrifuged at $200 \mathrm{x}$ g for $5 \mathrm{~min}$. Cell pellets was resuspended in $4 \%$ paraformaldehyde (Sigma-Aldrich) and fixed for $5 \mathrm{~min}$. Following washing three times in PBS (Gibco-BRL), cells were incubated with $10 \mu 1$ Hochest 33258 (Sigma-Aldrich) for $30 \mathrm{~min}$. Cells were then added to slides and observed under a fluorescence microscope (LSM710; Carl Zeiss Microscopy GmbH, Jena, Germany). For each sample, 500 cells were counted in order to calculate the percentage of apoptotic cells. Experiments were performed in triplicate.

Flow cytometric analysis. SGC7901 cells were treated with evodiamine at concentrations of $0,3,6,12,24$ and $48 \mu \mathrm{mol} / 1$ for $24 \mathrm{~h}$. Cells were then collected and adjusted to a density of $1 \times 10^{6} \mathrm{cells} / \mathrm{ml}$. Following centrifugation at $200 \mathrm{x}$ g for $5 \mathrm{~min}$, the supernatant was discarded and cells were resuspended in $100 \mu \mathrm{l}$ precooled PBS. Annexin V-fluorescein isothiocyanate (FITC; $5 \mu$; Nanjing Keygen Biotech., Co., Ltd., Nanjing, China) and propidium iodide (PI; $10 \mu 1$; Nanjing Keygen Biotech., Co., Ltd.) were then added to the cells and incubated in the dark for $15 \mathrm{~min}$ at room temperature. Following which, $400 \mu \mathrm{l}$ PBS was added and the apoptotic cells were analyzed by flow cytometry (BD FACSCanto II; BD Biosciences, Franklin Lakes, NJ, USA).

Reverse transcription polymerase chain reaction (RT-PCR). Total RNA was extracted from the cells treated with various concentration of evodiamine using TRIzol ${ }^{\circledR}$ (Invitrogen Life Technologies, Carlsbad, CA, USA) according to the
Table I. Evodiamine inhibits SGC7901 cell growth.

\begin{tabular}{cc}
\hline Evodiamine $(\mu \mathrm{mol} / \mathrm{l})$ & Inhibition $(\%)$ \\
\hline 0 & $0.00 \pm 4.57$ \\
3 & $17.12 \pm 4.13^{\mathrm{a}}$ \\
6 & $39.37 \pm 5.61^{\mathrm{a}}$ \\
12 & $61.21 \pm 5.66^{\mathrm{a}}$ \\
24 & $77.40 \pm 3.69^{\mathrm{a}}$ \\
48 & $80.01 \pm 5.39^{\mathrm{a}}$ \\
\hline
\end{tabular}

Values are presented as the mean \pm standard deviation. ${ }^{\text {a }}<0.05$ vs. $0 \mu \mathrm{mol} / 1$ evodiamine.

Table II. Evodiamine induces SGC7901 cell apoptosis.

\begin{tabular}{lcc}
\hline $\begin{array}{l}\text { Evodiamine } \\
(\mu \mathrm{mol} / \mathrm{l})\end{array}$ & $\begin{array}{c}\text { Early } \\
\text { apoptosis }(\%)\end{array}$ & $\begin{array}{c}\text { Late apoptosis } \\
\text { and necrosis }(\%)\end{array}$ \\
\hline 0 & $0.67 \pm 0.16$ & $1.49 \pm 0.23$ \\
3 & $8.54 \pm 1.28^{\mathrm{a}}$ & $4.36 \pm 0.64^{\mathrm{a}}$ \\
6 & $13.69 \pm 2.71^{\mathrm{a}}$ & $10.43 \pm 2.01^{\mathrm{a}}$ \\
12 & $20.42 \pm 3.45^{\mathrm{a}}$ & $16.79 \pm 3.06^{\mathrm{a}}$ \\
24 & $31.66 \pm 5.13^{\mathrm{a}}$ & $23.83 \pm 4.11^{\mathrm{a}}$ \\
48 & $44.35 \pm 7.34^{\mathrm{a}}$ & $32.54 \pm 5.48^{\mathrm{a}}$ \\
\hline
\end{tabular}

Values are presented as the mean \pm standard deviation. ${ }^{\mathrm{a}} \mathrm{P}<0.05$ vs. $0 \mu \mathrm{mol} / \mathrm{l}$ evodiamine.

manufacturer's instructions and stored at $-80^{\circ} \mathrm{C}$ until further use. Following denaturation in diethylpyrocarbonate-treated water (Sangon Biological Engineering Technology and Services Co., Ltd.) for $10 \mathrm{~min}$ at $70^{\circ} \mathrm{C}, 2 \mu \mathrm{g}$ total RNA was reverse-transcribed into complementary (c)DNA in a reaction volume of $20 \mu \mathrm{l}$, which contained 1X RT buffer, 20 Units RNase inhibitor, $50 \mathrm{mM}$ deoxynucleotides (dNTPs), 200 Units Moloney murine leukemia virus reverse transcriptase and $0.5 \mu \mathrm{g}$ oligo (deoxythymine) ${ }_{18}$ primer (all obtained from Promega Corporation, Madison, WI, USA). The reactions was incubated at $42^{\circ} \mathrm{C}$ for $60 \mathrm{~min}$ and then inactivated at $95^{\circ} \mathrm{C}$ for $10 \mathrm{~min}$.

Polymerase chain reaction amplification. Each experiment included samples containing no reverse transcriptase, as negative controls, to exclude amplification from contaminated genomic DNA.Primers (Sangon Biological Engineering Technology and Services Co., Ltd) used for PCR amplification were as follows: Survivin forward, 5'-TTTCTCAAGGACCACCGCA-3' and reverse, 5'-CAACCGGACGAATGCTTTTT-3'; Caspase-3 forward, 5'-TGCTTCTGAGCCATGGTGAA-3' and reverse, 5'-TGGCACAAAGCGACTGGAT-3'; and GADPH forward, 5'-ACCACAGTCCATGCCATCAC-3' and reverse, 5'-TCCACCACCCTGTTGCTGTA-3'. PCR amplification was performed using a PTC 225 thermal cycler (MJ Research, St. Bruno, QC, Canada) in a volume of $50 \mu 1$, which consisted of $1 \mu \mathrm{l}$ reaction cDNA mixture, $10 \mathrm{pmol}$ each primer, 

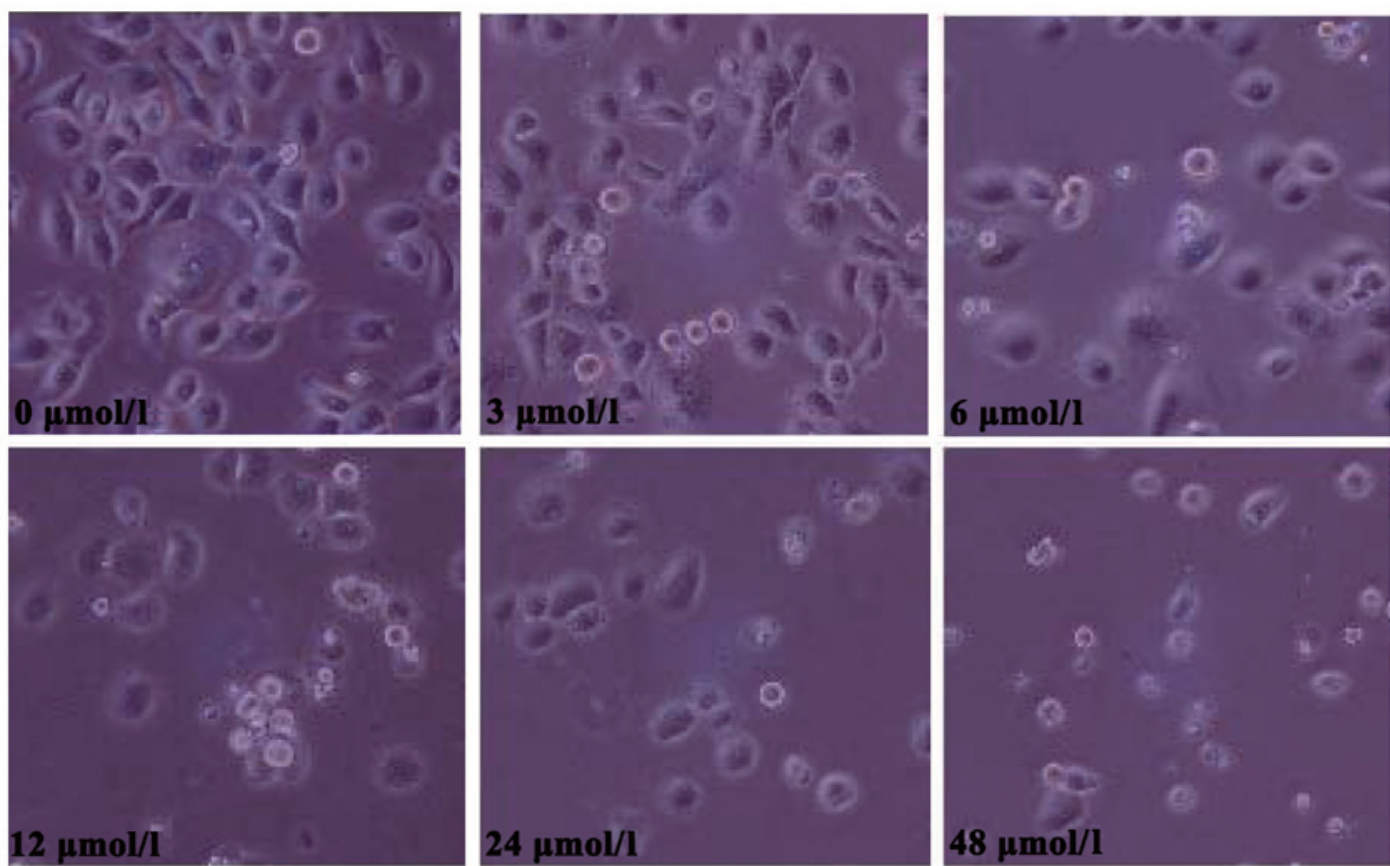

Figure 1. Morphological changes of SGC7901 gastric cancer cells following treatment with various concentrations of evodiamine $(0,3,6,12,24$ and $48 \mu$ mol/l) Images were captured using an inverted phase contrast microscope (magnification, x200).
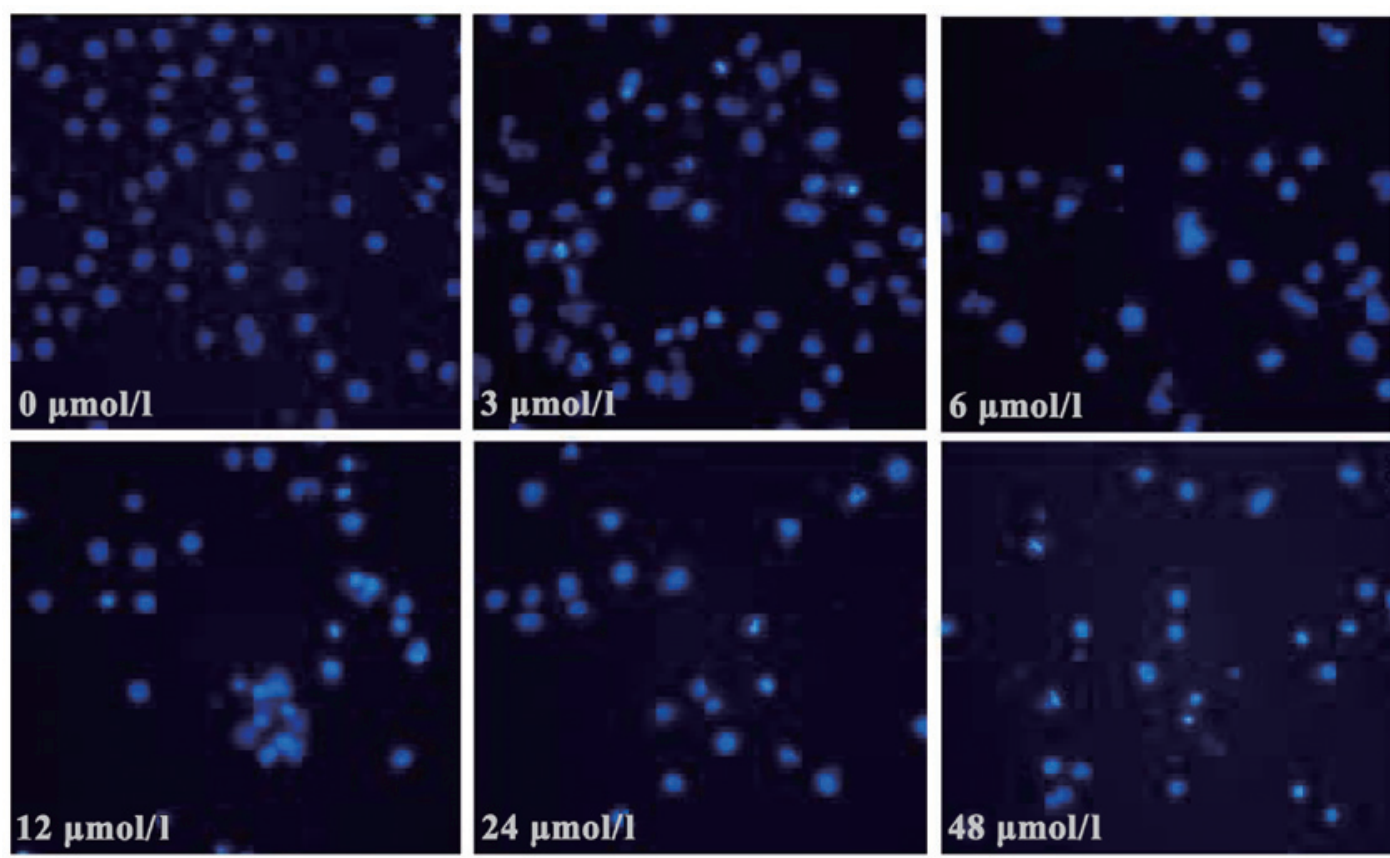

Figure 2. Fluorescence microscopy images of Hochest 33258-stained SGC7901 gastric cancer cells following treatment with various concentrations of evodiamine $(0,3,6,12,24$ and $48 \mu \mathrm{mol} / \mathrm{l})$ (magnification, $\mathrm{x} 200)$.

$200 \mathrm{mM}$ each dNTP, $2 \mathrm{mM} \mathrm{MgCl} 2,10 \mathrm{mM}$ Tris- $\mathrm{HCl}(\mathrm{pH} 8.3)$, $50 \mathrm{mM} \mathrm{KCl}$ and 2 Units Taq DNA polymerase (Sangon Biological Engineering Technology and Services Co., Ltd.). The amplification was composed of 35 cycles of $94^{\circ} \mathrm{C}$ for $40 \mathrm{sec}, 57^{\circ} \mathrm{C}$ for $40 \mathrm{sec}$ and $72^{\circ} \mathrm{C}$ for $1 \mathrm{~min}$, followed by a full extension cycle of $72^{\circ} \mathrm{C}$ for $5 \mathrm{~min}$. In each experiment, a negative control was included ( $0 \mu \mathrm{mol} / 1$ evodiamine). PCR products were then electrophoresed on $1.2 \%$ agarose gels (Sangon Biological Engineering Technology and Services
Co., Ltd.), stained with ethidium bromide (Sangon Biological Engineering Technology and Services Co., Ltd.) and images were captured using an ultraviolet transilluminator (CUV20; Cell Biosciences, Inc., Santa Clara, CA, USA). Results were expressed for each sample as band intensity relative to that of GAPDH.

Statistical analysis. Data are presented as the mean \pm standard deviation. All data were analyzed using a two-tailed 

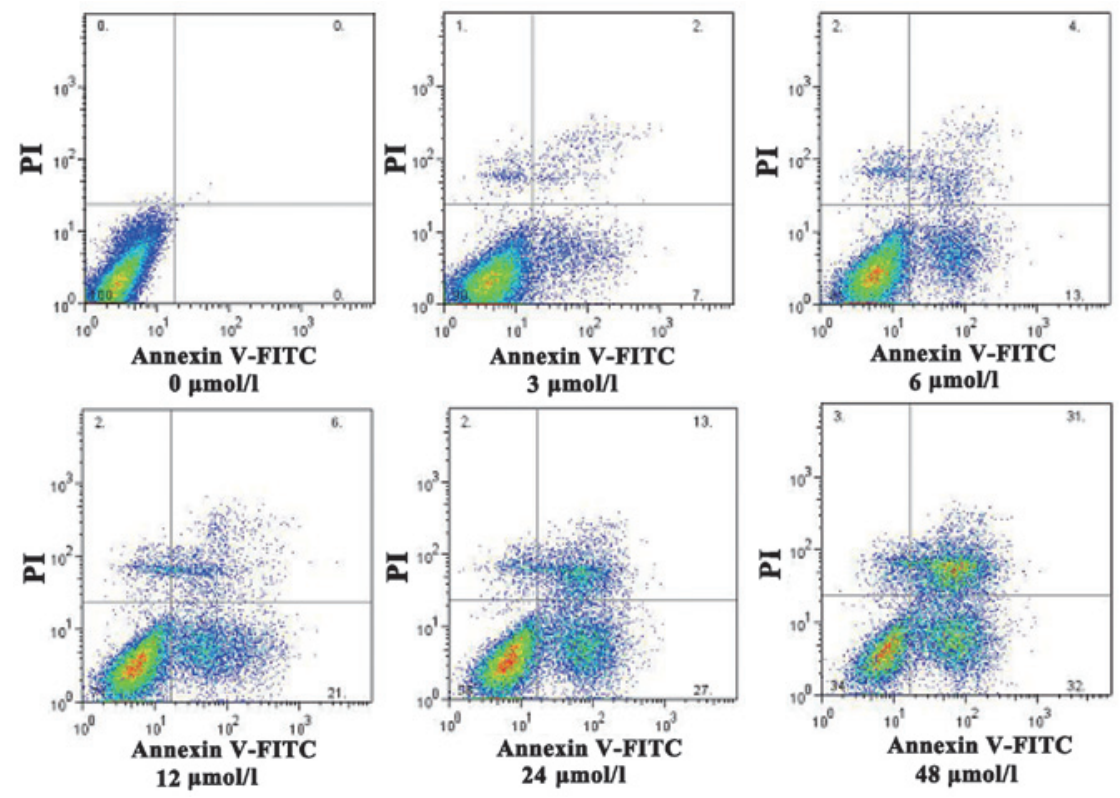

Figure 3. Evodiamine-induced apoptosis of SGC7901 gastric cancer cells. Flow cytometric analysis with Annexin V-FITC/PI double staining was used to investigate apoptosis in SGC7901 cells treated with various concentrations of evodiamine $(0,3,6,12,24$ and $48 \mu$ mol/l). FITC, fluorescein isothiocyanate; PI, propidium iodide.
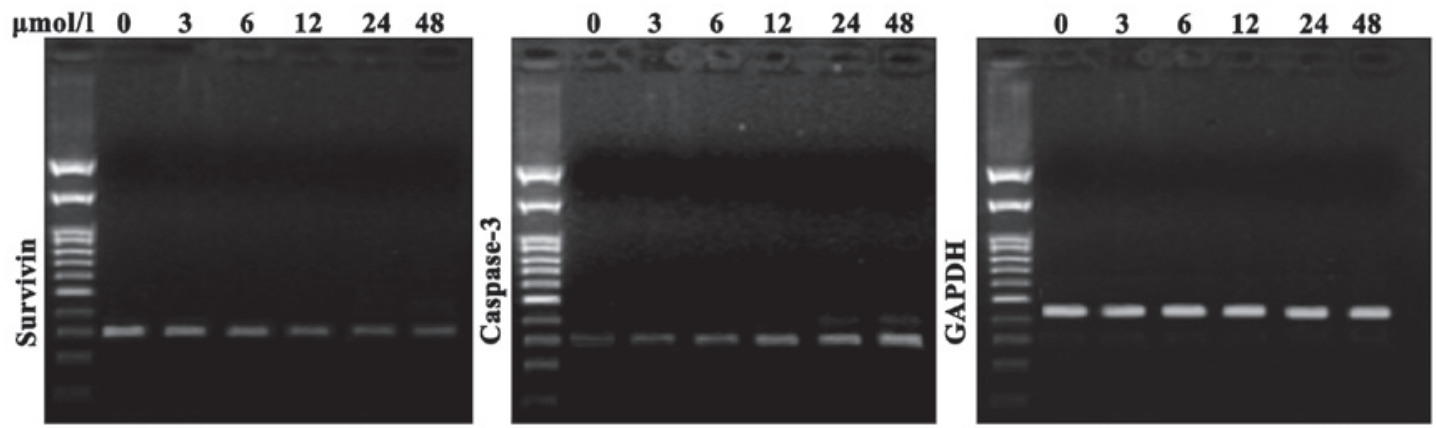

Figure 4. Survivin and caspase-3 messenger RNA expression in SGC7901 gastric cancer cells treated with various concentration of evodiamine (0, 3, 6, 12, 24 and $48 \mu \mathrm{mol} / \mathrm{l})$. GAPDH was used as a loading control.

unpaired Student's t-test and all statistical analyses were performed using SPSS 16.0 software (SPSS, Inc., Chicago, IL, USA). $\mathrm{P}<0.05$ was considered to indicate a statistically significant difference.

\section{Results}

Evodiamine inhibits gastric cancer cell proliferation. The growth of SGC7901 cells was demonstrated to be significantly inhibited following evodiamine treatment compared with that of the control group $(\mathrm{P}<0.05)$, with the inhibition rate gradually increasing in a dose-dependent manner (Table I).

Evodiamine induces gastric cancer cell apoptosis. Morphological changes observed in SGC7901 cells following evodiamine treatment are shown in Fig. 1. Treated cells exhibited a rounded shape; in addition, shrinkage, nuclear condensation and fragmentation were observed in evodiamine-treated cells, while the negative control cells had an irregular shape (fusiform or polygonal) and certain cells were integrated to form colonies. The apoptosis of SGC7901 cells was also observed under a fluorescent microscope. Following $24 \mathrm{~h}$ of evodiamine incubation, SGC7901 cells demonstrated signs of shrinkage, cytoplasmic concentration, nuclei pyknosis, chromatin margination and the formation of apoptotic bodies (Fig. 2). Apoptotic cells were quantified and the results demonstrated that evodiamine significantly increased the rate of early and late apoptosis or necrosis in SGC7901 cells in a dose-dependent manner $(\mathrm{P}<0.05)$ (Table II). In addition, as shown in Fig. 3, increasing concentrations of evodiamine resulted in an increase in the early apoptotic rate of SGC7901 cells, as determined by Annexin V-FITC/PI double staining (Fig. 3).

Evodiamine attenuates gastric cancer cell growth through deregulation of survivin and caspase-3. As shown in Fig. 4, compared with the negative control cells, SGC7901 cells treated with evodiamine exhibited a decreased expression of survivin messenger (m)RNA; in addition, survivin expression was further decreased with increasing concentrations of evodiamine. Furthermore, compared with the negative control group, evodiamine gradually upregulated the expression of 
caspase-3 mRNA in SGC7901 cells in a dose-dependent manner following $24 \mathrm{~h}$ of incubation (Fig. 4).

\section{Discussion}

The present study aimed to investigate the role of evodiamine, a natural active ingredient of the Traditional Chinese medicine Evodia rutaecarpa, in gastric cancer cells. The results revealed that evodiamine inhibited the proliferation of SGC7901 cells. In addition, using inverted phase contrast microscopy and fluorescence microscopy, cell shrinkage, concentrated cytoplasm, pyknotic nuclei, chromatin margination, nuclear fragmentation and the formation of apoptotic bodies were observed in evodiamine-treated SGC7901 cells.

Previous studies have reported a close association between apoptosis and tumor development $(12,13)$. Therefore, the exploration of the mechanisms underlying drug-induced tumor cell apoptosis is essential for improving drug efficacy and the development of novel anticancer drugs. In the present study, it was demonstrated that gastric cancer cells treated with evodiamine exhibited a concentration-dependent increase in the number of apoptotic and necrotic cells, as determined using Annexin V-FITC/PI double staining.

Survivin is a member of the inhibitors of apoptosis proteins gene family, which has been reported to have important roles in the inhibition of apoptosis and is predominantly expressed in the mitotic cycle of cells in $S$ and $G_{2} / M$ phase (4). Survivin was demonstrated to be widely expressed in a variety of tumor tissues; in addition, the expression of survivin was found to be deregulated in cancer cells $(14,15)$. Survivin expression in gastric cancer was reported to be negatively correlated with apoptosis index (16), which is concurrent with the results of the present study that showed a gradual decrease in survivin mRNA expression with increased concentrations of evodiamine. This therefore suggested that evodiamine may decrease survivin mRNA expression. Caspases are cysteine proteases, which were named due to their strict specificity for cleaving peptide sequences at the C-terminal of aspartic acid residues (17). Once activated, effector caspases induce a series of hydrolysis reactions, which ultimately lead to the initiation of cell death (18). It is widely recognized that caspase- 3 is a key protease and an essential effector agent involved in hydrolysis, which acts alone or in combination with the apoptosis-associated proteins $(19,20)$. Activation of caspase-3 inevitably leads to the initiation of cascades, which result in the induction of apoptosis (21). The results of the present study demonstrated that mRNA levels of caspase-3 in SGC7901 cells were gradually increased with increasing concentrations of evodiamine.

The results of the present study indicated that evodiamine-induced SGC7901 cell apoptosis may be associated with decreased expression levels of survivin and increased expression levels of caspase-3. Thus, evodiamine may present a potential treatment for gastric cancer. In addition, further studies are required to investigate the combined therapeutic effect of chemotherapy and evodiamine for the treatment of gastric cancer.

\section{Acknowledgements}

The present study was supported by grants from Zhejiang Provincial Natural Science Foundation of China (nos. LY14H160027 and LQ12H16009) and the Science and Technology Bureau of Zhejiang Province (no. 2013C33137).

\section{References}

1. O'Brien LE and Bilder D: Beyond the niche: tissue-level coordination of stem cell dynamics. Annu Rev Cell Dev Biol 29: 107-136, 2013.

2. Bissell MJ and Radisky D: Putting tumours in context. Nat Rev Cancer 1: 46-54, 2001.

3. Potter JD: Morphogens, morphostats, microarchitecture and malignancy. Nat Rev Cancer 7: 464-474, 2007.

4. Altieri DC: Survivin, cancer networks and pathway-directed drug discovery. Nat Rev Cancer 8: 61-70, 2008.

5. Xiao BY, Mao SJ and Li XD: Variations in the composition of Fructus Evodiae after processing with Radix Glycyrrhizae extract. Chin J Integr Med 18: 782-787, 2012.

6. Chiou WF, Ko HC and Wei BL: Evodia rutaecarpa and three major alkaloids abrogate influenza a virus (H1N1)-induced chemokines production and cell migration. Evid Based Complement Alternat Med 2011: 750513, 2011.

7. Wiart C: A note on Evodia rutaecarpa. Phytomedicine 19: 1244, 2012

8. Liu ZL, Liu QZ, Du SS and Deng ZW: Mosquito larvicidal activity of alkaloids and limonoids derived from Evodia rutaecarpa unripe fruits against Aedes albopictus (Diptera: Culicidae). Parasitol Res 111: 991-996, 2012.

9. Cai GX, Huang D, Li SX, Xu F, Wang L, et al: Comparative analysis of essential oil components of Evodia rutaecarpa (Juss.) Benth. var. officinalis (Dode) Huang and Evodia rutaecarpa (Juss.) Benth. Nat Prod Res 26: 1796-1798, 2012.

10. Chen MC, Yu CH, Wang SW, Pu HF, Kan SF, et al: Anti-proliferative effects of evodiamine on human thyroid cancer cell line ARO. J Cell Biochem 110: 1495-1503, 2010.

11. Zhang Y, Wu LJ, Tashiro S, Onodera S and Ikejima T: Evodiamine induces tumor cell death through different pathways: Apoptosis and necrosis. Acta Pharmacol Sin 25: 83-89, 2004.

12. Cotter TG: Apoptosis and cancer: the genesis of a research field. Nat Rev Cancer 9: 501-507, 2009.

13. Ashkenazi A: Targeting the extrinsic apoptotic pathway in cancer: lessons learned and future directions. J Clin Invest 125: 487-489, 2015.

14. Carter BZ, Milella M, Altieri DC and Andreeff M: Cytokine-regulated expression of survivin in myeloid leukemia. Blood 97: 2784-2790, 2001.

15. Adida C, Recher C, Raffoux E, Daniel MT, Taksin AL, et al: Expression and prognostic significance of survivin in de novo acute myeloid leukaemia. Br J Haematol 111: 196-203, 2000.

16. Lu CD, Altieri DC and Tanigawa N: Expression of a novel antiapoptosis gene, survivin, correlated with tumor cell apoptosis and p53 accumulation in gastric carcinomas. Cancer Res 58: 1808-1812, 1998.

17. Shalini S, Dorstyn L, Dawar S and Kumar S: Old, new and emerging functions of caspases. Cell Death Differ 22: 526-539, 2015.

18. Vandenabeele P, Galluzzi L, Vanden Berghe T and Kroemer G: Molecular mechanisms of necroptosis: an ordered cellular explosion. Nat Rev Mol Cell Biol 11: 700-714, 2010.

19. D'Amelio M, Cavallucci V and Cecconi F: Neuronal caspase-3 signaling: not only cell death. Cell Death Differ 17: 1104-1114, 2010.

20. Wakeyama H, Akiyama T, Kadono Y, Nakamura M, Oshima Y, Nakamura K and Tanaka S: Posttranslational regulation of Bim by caspase-3. Ann NY Acad Sci 1116: 271-280, 2007.

21. Lakhani SA, Masud A, Kuida K, et al: Caspases 3 and 7: key mediators of mitochondrial events of apoptosis. Science 311: 847-851, 2006. 